\title{
Achievement of high-cyclability and high-voltage Li-metal batteries by heterogeneous SEI film with internal ionic conductivity/external electronic insulativity hybrid structure
}

\author{
Shao-Jian Zhang ${ }^{\mathrm{a}, \dagger}$, Zu-Wei Yin ${ }^{\mathrm{a}, \mathrm{f}, \dagger}$, Zhan-Yu Wu $^{\mathrm{d}, \dagger}$, Dan Luo ${ }^{\mathrm{b}}$, Yi-Yang Hu ${ }^{\mathrm{a}}$, Jin-Hai You ${ }^{\mathrm{a}}$, Bingkai \\ Zhang $^{\mathrm{g}}$, Kai-Xuan Li ${ }^{\mathrm{c}}$, Jia-Wei Yan ${ }^{\mathrm{c}}$, Xue-Rui Yang ${ }^{\mathrm{a}}$, Xiao-Dong Zhou ${ }^{\mathrm{e}}$, Sandrine Zanna ${ }^{\mathrm{d}}$, Philippe \\ $\operatorname{Marcus}^{\mathrm{d}}$, Feng Pan ${ }^{\mathrm{f}}$, Jolanta Światowska ${ }^{\mathrm{d}, *}$, Shi-Gang Sun ${ }^{\mathrm{c}, *}$, Zhongwei Chen ${ }^{\mathrm{b}, *}$, Jun-Tao Li ${ }^{\mathrm{a}, *}$
}

Corresponding authors:

E-mail addresses: jolanta.swiatowska@chimieparistech.psl.eu (J. Światowska), sgsun@xmu.edu.cn (S.-G. Sun), zhwchen@uwaterloo.ca (Z. Chen), jtli@xmu.edu.cn (J.-T. Li).

\footnotetext{
${ }^{a}$ College of Energy, Xiamen University, Xiamen 361005, China

${ }^{\mathrm{b}}$ Department of Chemical Engineering, Waterloo Institute of Nanotechnology, University of Waterloo, Waterloo, ON N2L 3G1, Canada

${ }^{\mathrm{c}}$ State Key Lab of Physical Chemistry of Solid Surface, College of Chemistry and Chemical Engineering, Xiamen University, Xiamen 361005, China

d PSL Research University, CNRS - Chimie ParisTech, Institut de Recherche de Chimie Paris (IRCP), 11 rue Pierre et Marie Curie, 75005 Paris, France

${ }^{\mathrm{e}}$ Institute for materials Research and Innovation, Department of Chemical Engineering, University of Louisiana at Lafayette, Lafayette, LA 70503, United States ${ }^{\mathrm{f}}$ School of Advanced Materials, Peking University, Shenzhen Graduate School, Shenzhen, 518055, China

${ }^{\mathrm{g}}$ School of Chemical Engineering and Light Industry, Guangdong University of Technology, Guangzhou 510006, China
}

\begin{abstract}
Establishing electronic hinder/ionic transfer pathway in SEI film is key issue for high-performance Li-metal an-odes (LMA), which requires the SEI with high ionic conductivity to enable fast $\mathrm{Li}^{+}$diff usion and regulated $\mathrm{Li}$ deposition behavior, and poor electronic conductivity to block the electrolyte consumption. Herein, we propose a strategy to construct heterogeneous SEI via selective reduction of electrolytes components to improve Li stability and suppress dendrite growth. The inner N-rich sub-layer of SEI film enables fast $\mathrm{Li}^{+}$transportation for nodule-like Li deposition while the outer C-rich sub-layer of SEI film exhibits an electronic insulation property to block electrolyte decomposition. This hybrid SEI endows the LMA with high Coulombic efficiency (99.0\%), long lifespan, and dendrite suppression. Theoretical calculations, XPS and AFM were employed to examine the heterogeneous SEI structure and clarify its formation mechanism. A high-capacity retention of $91.6 \%$ after 160 cycles at $0.5 \mathrm{C}$ in $\mathrm{LiCoO}_{2} / \mathrm{Li}$ pouch cells with ultra-thin $\mathrm{Li}$ anodes (25 m) and low $\mathrm{N} / \mathrm{P}$ ratio (1.67), and an excellent performance with $85.7 \%$ capacity retention after 300 cycles at higher charge potential (4.5 V) was also obtained. The insight in heterogeneous SEI formation provides new opportunities for rational electronic/ionic transfer pathway construction for achieving high-performance Li-metal batteries.
\end{abstract}

Keywords: 


\section{Introduction}

Rechargeable lithium metal batteries are a transformative technology that could revolutionize the energy storage sector because of their high theoretical specific capacity (3860 $\mathrm{mAh}^{-1}{ }^{-1}$ ) and low redox potential ( $-3.04 \mathrm{~V}$ vs. standard hydrogen electrode) of the Li-metal anode [1]. The Li-metal anode is capable of coupling with a variety of cathodes, including traditional layered oxides ( $440 \mathrm{Wh} \mathrm{Kg}^{-1}$ ), sulfur (650 Wh $\mathrm{Kg}^{-1}$ ) and oxygen (950 $\mathrm{Wh} \mathrm{Kg}^{-1}$ ), [2] but continues to exhibit two challenging issues: (1) limited cyclability and Coulombic efficiency (CE) due to the continuous interaction between Li metal and electrolyte and (2) formation of uneven dendrites and instable Li/electrolyte interface. The latter results in active Li loss and possible penetration of dendrites through the separator, leading to an internal short circuit of batteries and the possibility of catching fire [3].

Tremendous eff orts have been made to address the obstacles in application of Li metal anodes. Strategies such as artificial protective films [4-9], stable porous host skeletons [10-13], electrolytes optimization [14-15], solid-state electrolytes [16-19] etc. were studied to suppress dendrite growth and enhance the cycling performance of Li metal batteries. Electrolyte optimization has proven itself to a simple but eff ective method to create high-performance Li metal batteries. It was reported that increasing the concentration of $\mathrm{Li}$ salt can improve the compatibility between $\mathrm{Li}$ and electrolytes [20-21]. However, high viscosity and low ionic conductivities impede the charge and mass transportation, which results in sluggish reaction kinetics and hinders its practical application. Another approach is to adjust the chemical and physical properties of the Li electrolyte interface via film-forming electrolyte components or functional additives [22-25].

A fast $\mathrm{Li}$-ionic transfer ability for $\mathrm{SEI}$ film on the $\mathrm{Li}$ anodes can lead to a homogeneous $\mathrm{Li}$ ion flux and increase the ionic concentration beneath of the SEI film, which aids with uniform Li deposition [26]. While the surface electron leakage would result in the electron acquisition of electrolyte components, which give rise to the further reduction of electrolyte [27]. It is reported that only $2 \mathrm{~nm} \mathrm{LiF}$ or $3 \mathrm{~nm}$ $\mathrm{Li}_{2} \mathrm{CO}_{3}$ are thick enough to block electron tunneling, which significantly attributes to block pathway for SEI generation, leading to less irreversible capacity loss at initial cycles [28]. Thus, a desirable SEI film for Li metal anodes needs the combination of enhanced ability for $\mathrm{Li}$ ion transfer and good passivated properties. However, the investigation of rational design of SEI film with heterogenous electronic insulated/ionic conductive structure is still missing.

Batteries with high-energy-density commercial cathodes (high-voltage $\mathrm{LiCoO}_{2}$, etc.) matching with ultra-thin $\mathrm{Li}$ anodes can be one of the most promising approaches for the practical application of Li-metal batteries. However, combination of high-voltage tolerance and stable $\mathrm{Li}$ interface stability still is the main obstacle. Commercial carbon-ate electrolytes (i.e. $1 \mathrm{M} \mathrm{LiPF}_{6}$ in EC/DMC/EMC $1 / 1 / 1 \quad v / v / v$ ) deliver high-voltage stable potential window, while poor Li stability [29]. And ester-based electrolytes (i.e. 1 M LiTFSI in DME/DOL) are more compatible with $\mathrm{Li}$, however, a narrow stable potential window limits their application. Tetra ethylene glycol dimethyl ether (TEGDME) is one of the promising candidates for electrolyte solvent in Li-metal-based batteries, which were able to deliver an excellent cycling performance in $\mathrm{Li}_{-} \mathrm{O}_{2}$ batteries with high-voltage tolerance (4.5 V) [2]. Unfortunately, TEGDME cannot form efficient SEI films on the Li anodes due largely to the porous Li structure formation. This leads to the continuous reaction with lithium and the formation of thick SEI film. Consequently, applying a TEGDME-based electrolyte results in a low Li CE and short battery lifetime [30]. Herein, rational design of the SEI film with heterogeneous electronic insulated/ionic conductive structure can remarkably enhance the Li stability of TEGDME-based electrolyte with a major leap in $\mathrm{Li} \mathrm{CE}$ from less than $20.0 \%$ to $99.0 \%$.

In our contribution, we propose a novel strategy to rationally design electronic/ionic transfer pathway in a heterogeneous SEI film via selective reduction of $\mathrm{LiNO}_{3}$ and $\mathrm{EC}$ components in electrolyte, which can efficiently regular Li deposition behavior and suppress interface side-reaction. Owing to the thermodynamically feasible reaction between metallic $\mathrm{Li}$ and $\mathrm{LiNO}_{3}$, the $\mathrm{LiNO}_{3}$ additive in electrolyte will fast consumption during repeating cycles. Besides, narrow band gap of $\mathrm{LiNO}_{3}$-induced products, $\mathrm{Li}_{\mathrm{x}} \mathrm{NO}_{\mathrm{y}}$, cannot prohibit the leaking electron, leading to the constantly electrolyte decomposition. Thus, the performance of the batteries in $\mathrm{LiNO}_{3}$-only electrolyte suffers fast degradation. Differently, some typical SEI constitutions, like $\mathrm{LiF}, \mathrm{Li}_{2} \mathrm{CO}_{3}$ etc. has a wide band gap, meaning the poor electronic conductivity, which can be desirable components to passivate SEI surface to prohibit the leaking electron. However, poor ionic conductivity of these components 
cannot pro-vide enough ionic transfer pathway to regular the Li ion flux, leading to the dendrite growth, and unstoppable breaking/repairing of SEI film. Aiming to suppress both dendrite and electrolyte consumption, one desirable SEI film can be a heterogeneous hierarchical structure with internal ionic conductivity and external electronic insulation. The internal sub-layer with fast ionic transfer pathway regular the Li deposition and suppress the dendrite, while external sub-layer with electronic insulation prevents the leaking electron and blocks the electrolyte de-composition. To our knowledge, $\mathrm{LiNO}_{3}$ has a smaller lowest unoccupied molecular orbital (LUMO) energy than ethylene carbonate (EC), meaning the prior reduction of $\mathrm{LiNO}_{3}$ with $\mathrm{Li}$ metal. Thus, we combined the $\mathrm{LiNO}_{3}$ additive and EC co-solvent to take advantage of the high-voltage stability in TEGDME, leading to a desirable electrolyte system comprised of both Li stability and antioxidation properties. The components of internal SEI sub-layer, which dominated by $\mathrm{LiNO}_{3}$ re-duction products, $\mathrm{Li}_{\mathrm{X}} \mathrm{NO}_{\mathrm{y}}$ or $\mathrm{Li}_{3} \mathrm{~N}$, can provide enough Li ion diffusion pathway, and the components of external SEI sub-layer, mainly constituted by EC or Li salt reduction products, $\mathrm{Li}_{2} \mathrm{CO}_{3}, \mathrm{LiF}$ etc. prohibits the decomposition of electrolyte. SEM results illustrate that the cycled Li anodes with a heterogeneous SEI film display nodule-like Li particles with less active Li loss and a tight cycled Li layer (6 m), which is much thinner than that in the bare TEGDME electrolyte $(136 \mathrm{~m})$ and EC or $\mathrm{LiNO}_{3}$-only electrolytes. The design of heterogeneous SEI film allows Li CE in EC/TEGDME50/50 ( $v / v$ ) with $0.1 \mathrm{M} \mathrm{LiNO}_{3}$ additive (with $0.5 \mathrm{M} \mathrm{LiTFSI/0.5} \mathrm{M} \mathrm{LiBOB} \mathrm{as} \mathrm{lithium} \mathrm{salts)} \mathrm{to} \mathrm{reach} 99.0 \%$. Stability of electrolyte was also investigated in pouch cell with high-loading $\mathrm{LiCoO}_{2}$ cathodes $\left(3 \mathrm{mAh} \mathrm{cm}^{-2}\right.$ ) and ultra-thin $\mathrm{Li}$ foils (25 $\left.\mathrm{m}\right)$, corresponding to a low $\mathrm{N} / \mathrm{P}$ (negative/positive) ratio of 1.67 , that can deliver an excellent cycling performance with a capacity retention of $91.6 \%$ after 160 cycles at 0.5 $\mathrm{C}$, holding great potential for practical application. A cycling stability with a capacity retention of $85.7 \%$ after 300 cycles was also observed in high-loading $\left(2.5 \mathrm{mAh} \mathrm{cm}^{-2}\right) \mathrm{LiCoO}_{2} / \mathrm{Li}$ full cells under high charge voltage of $4.5 \mathrm{~V}$, suggesting desirable Li utilization and antioxidation property of EC/TEGDME/LiNO 3 electrolyte. These results demonstrate that the heterogeneous SEI structure with different electronic/ionic diffusion abilities can be generated according to the selective reduction of electrolyte components, leading to the combination of anode stability and high-voltage tolerance.

\section{Results and discussion}

\subsection{The mechanism of heterogeneous SEI film formation}

Tunning of SEI structure could create high-performance Li anodes and excellent stability in Li-metal-based full cells configuration. In order to consider the high oxidation potential window and Li anode stability, TEGDME was applied to serve as the bulk solvent of electrolyte to acquire high-voltage electrolyte system, and heterogeneous SEI structure with internal ionic conductivity/external electronic insulation was directionally designed by controlling the reduction sequences of electrolyte components to achieve stable Li electrolyte interface and dendrite-free morphology. Hereien, $\mathrm{EC}$ and $\mathrm{LiNO}_{3}$ were adopted as the source of the formation of heterogeneous $\mathrm{SEI}$ structure. The LiNO 3 can be reduced prior to the EC, generating a $\mathrm{Li}_{\mathrm{X}} \mathrm{NO}_{\mathrm{y}}$-rich SEI near the surface of Li metal to create a fast ion transfer pathway. And EC further is decomposed in the outside shell of SEI film to block the electron transfer and passivate the SEI film.

The density functional theoretical (DFT) calculations were per-formed to evaluate the reducing activity of electrolyte components. As presented in Fig. 1a, the lowest unoccupied molecular orbital (LUMO) energy of $\mathrm{LiNO}_{3}$ is $-1.421 \mathrm{eV}$. Thus, another film-forming electrolyte component should have a higher LUMO energy, which enables $\mathrm{LiNO}_{3}$ to preferentially reduce on Li anodes. EC, a desirable film-forming molecule on anodes, which exhibits a LUMO energy of $-0.215 \mathrm{eV}$, can be reduced after $\mathrm{LiNO}_{3}$ to form an outer passivated layer on the $\mathrm{Li}$ an-ode. In particular, compared with EC, another film-forming additive, FEC (LUMO energy of - 0.8256 eV), displays a higher reduction potential than $\mathrm{EC}$, which would not reduce after $\mathrm{LiNO}_{3}$. Besides, main compounds decomposed by FEC is mainly dominated by LiF, which trends to guide filamentous Li morphology. Thus, the EC may be a better choice for this system. The TEGDMEbased electrolytes combining both co-solvent $\mathrm{EC}$ and additive $\mathrm{LiNO}_{3}$ were thoroughly investigated. Among several diff erent compositions of electrolyte, $50 \mathrm{Vol} \%$ TEGDME, $50 \mathrm{Vol}^{2} \mathrm{EC}$ and $0.1 \mathrm{M} \mathrm{LiNO}_{3}$ additive (EC/TEGDME-50/50+0.1 $\mathrm{M} \mathrm{LiNO}_{3}$ ) demonstrated the most interesting performance of $\mathrm{Li}$ anodes. The $\mathrm{Li}$ deposition curves in EC/TEGDME-50/50 and EC/TEGDME-50/50+0.1 $\mathrm{M}$ LiNO 3 were 
analyzed to investigate the reduction sequence of $\mathrm{EC}$ and $\mathrm{LiNO}_{3}$ (Fig. 1b). The deposition curve in EC/TEGDME-50/50 electrolyte exhibits a plateau around $0.5 \mathrm{~V}$, which can be associated with the reduction of the EC on the $\mathrm{Li}$ surface. After adding LiNO 3 , besides the EC reduction plateau, a new plateau appears at approximately $0.8 \mathrm{~V}$, corresponding to the reduction of $\mathrm{LiNO}_{3}$. The higher reduction potential of $\mathrm{LiNO}_{3}$ indicates that the SEI film formation of $\mathrm{LiNO}_{3}$ can occur before EC, proving that a heterogeneous SEI film can be directionally generated by selective reduction of the $\mathrm{LiNO}_{3}$ and EC.

The mechanism of forming heterogeneous SEI film is illustrated by schematic diagrams in Fig. 1c. The internal SEI sub-layer dominated by ionic conductor to provide a fast $\mathrm{Li}$ ion transfer channel, which enables uniform Li nucleas formation. For the external SEI sub-layer, electronic insulated constitutions block the electronic transfer, prohibits the electrolyte components capture the electron and be reduced by Li metal. Thus, uniform $\mathrm{Li}^{+}$flux can be realized on the $\mathrm{Li}$ surface and guides the $\mathrm{Li}$ deposition behavior, leading to a noudle-like $\mathrm{Li}$ morphology.
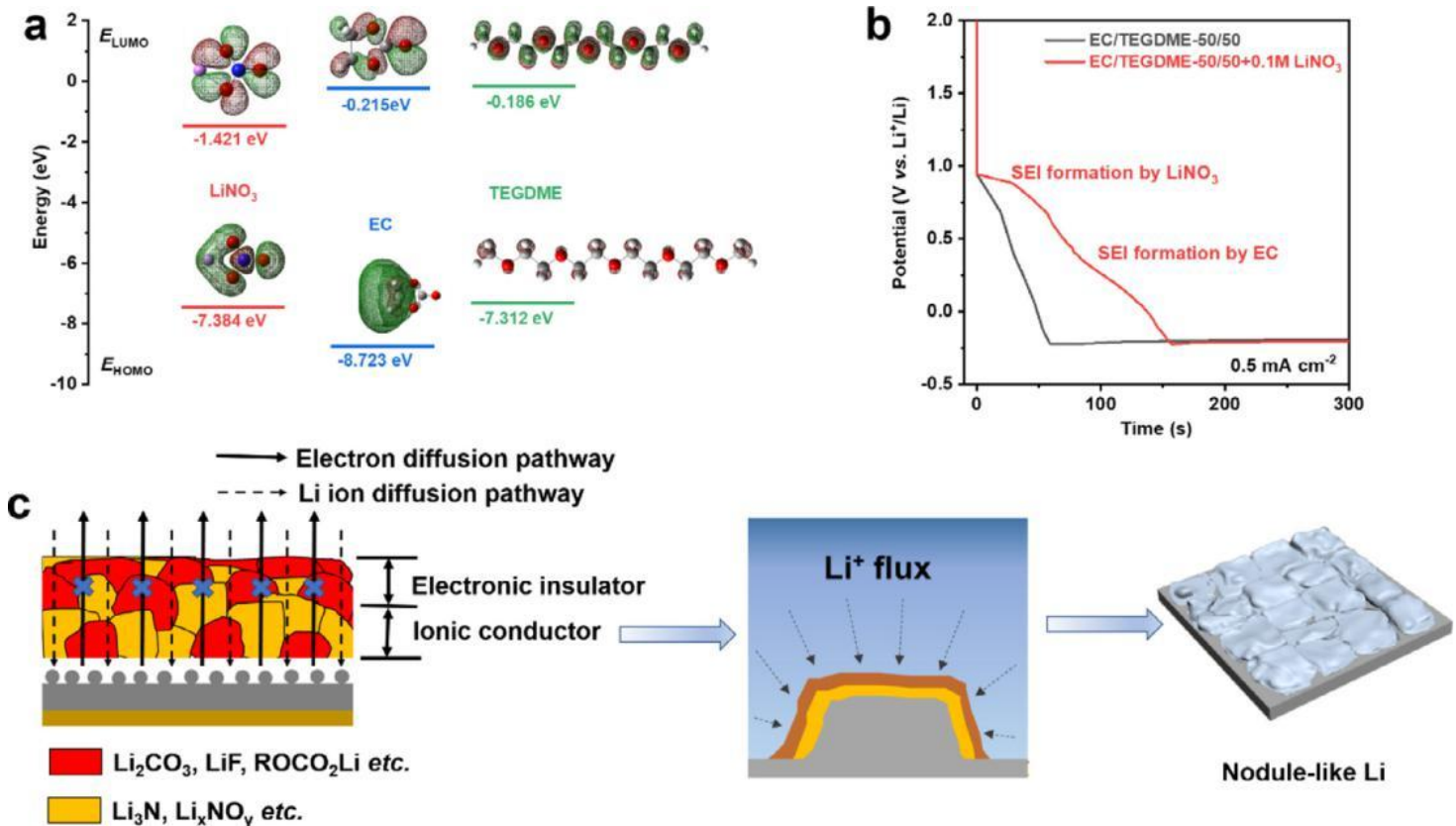

Nodule-like Li

Fig. 1. Schematic diagram of SEI formation. a) Highest occupied molecular orbital (HOMO) and lowest unoccupied molecular orbital (LUMO) energies and b) the typical Li deposition curves in EC/TEGDME-50/50 and EC/TEGDME-50/50+0.1 $\mathrm{M} \mathrm{LiNO}_{3}$ electrolytes. c) The schematic diagrams for the heterogeneous SEI structure.

\subsection{Identification of heterogeneous SEI structure}

The chemical and physical properties of SEI films play crucial roles in regulating morphology and elevating the electrochemical performance of Li metal anodes. To analyze the SEI layer composition and structure, the XPS in-depth analysis and Atomic Force Microscope (AFM) were carried on the Li electrode cycled in diff erent electrolytes.

The high-resolution C 1 s spectra, obtained on the surface Li metal cycled in EC/TEGDME-50/50+0.1 M LiNO3 (Fig. 2a), shows the main components of the SEI layer including peaks corresponding to -C-O-C- bonding, which can corresponds to poly(ethylene oxide) (PEO, 
$\left.\left.\mathrm{CH}_{2}-\mathrm{CH}_{2}-\mathrm{O}\right)_{\mathrm{n}^{-}}\right)$and/or $\mathrm{R} \underline{\mathbf{C}}-\mathrm{O}-\mathrm{CO}_{2} \mathrm{Li}$ at $\sim 286.5 \mathrm{eV},-\mathrm{C}=O$ bonding at $\sim 288.6 \mathrm{eV}$ and carbonate groups $\left(-\mathrm{CO}_{3}\right.$ and/or $\left.\mathrm{RC}-\mathrm{O}-\underline{\mathbf{C}} \mathrm{CO}_{2} \mathrm{Li}\right)$ at $\sim 289.6 \mathrm{eV}$ ). The presence of these $\mathrm{C}$ peaks originates from the electrochemical reduction of EC [31,32], however, the high intensity of carbon peak at $\sim 286.5 \mathrm{eV}$ can be related to the reductive decomposition of TEGDME [33]. The presence of hydrocarbon ( $285 \mathrm{eV}(\mathrm{C}-\mathrm{C}))$ can be related to the typical surface contamination usually present on the electrode surface. The in-depth composition (after sputtering of the SEI layer, Fig. 2a) shows the decrease intensity of the higher binding energy peaks (at B.E. higher that $286 \mathrm{eV}$ ) and increase of the hydrocarbon peak at $285.0 \mathrm{eV}$. Moreover, a new peak appears at lower binding energy (of around $283.5 \mathrm{eV}$ ), which can be attributed to carbides (C-Li). [34,35]

The SEI layer carbon-oxygen containing species was also confirmed by analysis of O $1 \mathrm{~s}$ peak (Fig. 2b), showing three peaks at $\sim 530.5$ $\mathrm{eV}$ corresponding to $-(\mathrm{C}-\mathrm{O})$, at $532.5 \mathrm{eV}$ to $-\mathrm{C}-\mathrm{O}-\mathrm{C}$ - (including $\mathrm{RC}-\underline{\mathbf{O}}-\mathrm{CO}_{2} \mathrm{Li}$ and/or $\mathrm{PEO}\left(\mathrm{CH}_{2}-\mathrm{CH}_{2}-\mathrm{O}\right)_{\mathrm{n}^{-}}$) and the peak at $\sim 534.0 \mathrm{eV}$, which can be attributed to poly $\left(\mathrm{CO}_{3}\right), \mathrm{Li}_{2} \mathrm{CO}_{3}$ and/or $\mathrm{RC}-\mathrm{O}-\mathrm{C} \underline{\mathbf{O}}_{2} \mathrm{Li}$ [32]. The $\mathrm{O} 1 \mathrm{~s}$ peak at $532.5 \mathrm{eV}$ can be also overlayered with the peak corresponding to $\mathrm{N}-\mathrm{O}$ bonding [36]. As discussed in the literature one of the possible SEI layer components formed on $\mathrm{Li}$ anode in the presence of carbon-ate electrolytes can be the polycarbonates, showing the high $\mathrm{O} 1 \mathrm{~s}$ and $\mathrm{C} 1 \mathrm{~s}$ binding energy peaks (at around $534 \mathrm{eV}$ and over $291 \mathrm{eV}$, respectively). [24,37] However, here, no high binding energy C $1 \mathrm{~s}$ peaks were observed, thus the presence of polycarbonates can be discarded (Fig. 2a). Concerning the $\mathrm{O} 1 \mathrm{~s}$ peak, the low binding energy peak at around $529 \mathrm{eV}$ corresponding to $\mathrm{Li}_{2} \mathrm{O}[38,39]$ can be also observed. The in-depth analysis (Fig. 2d) shows the enrichment of the bulk SEI layer in $\mathrm{Li}_{2} \mathrm{O}$ as well as PEO $\left.\left(\mathrm{CH}_{2}-\mathrm{CH}_{2}-\mathrm{O}\right)_{n^{-}}\right)$ components.

The SEI layer formed on the $\mathrm{Li}$ negative electrode cycled in EC/TEGDME-50/50+0.1 $\mathrm{M} \mathrm{LiNO}_{3}$ is also enriched in the $\mathrm{N}$-containing species as shown by N $1 \mathrm{~s}$ spectra in Fig. 2c. The $\mathrm{N} 1 \mathrm{~s}$ peak at around $399 \mathrm{eV}$ is quite large (FWHM of more than $2 \mathrm{eV}$ ), thus, the presence of diff erent products of $\mathrm{LiNO}_{3}$ decomposition can be present such as $\mathrm{Li}_{3} \mathrm{~N}$ and $\mathrm{Li}_{\mathrm{X}} \mathrm{NO}_{\mathrm{y}}$ as previously demonstrated on $\mathrm{Li}$ electrode cycled in $\mathrm{FEC} / \mathrm{LiNO}_{3}$ electrolyte [40]. As shown there, $\mathrm{Li}_{\mathrm{X}} \mathrm{NO}_{\mathrm{y}} / \mathrm{Li}_{3} \mathrm{~N}$ contributes to formation of uniform lithium deposition and ionic conductivity of the SEI layer [41]. The second N $1 \mathrm{~s}$ peak at higher binding energy of around $401 \mathrm{eV}$ can be attributed to $\mathrm{LiNO}_{2}$ [36]. The in-depth analysis (Fig. 2d) shows the increase of $\mathrm{N}$-like components while a decrease of $\mathrm{C}$-like components (as discussed) above can be observed in the inner part of the SEI layer.
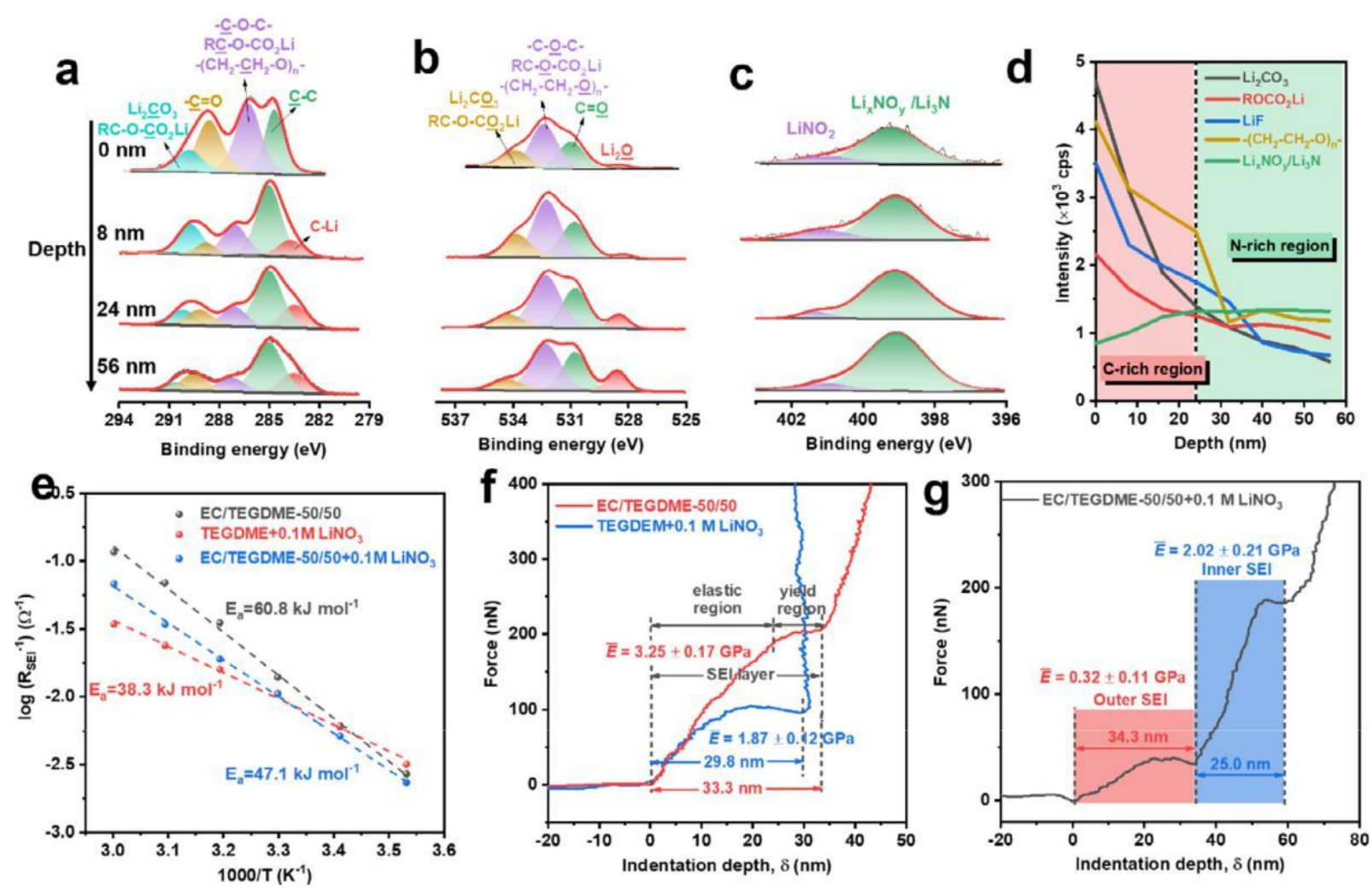
Fig. 2. Chemical and physical analyzation of SEI. The in-depth XPS spectra of SEI layer formed on Li metal cycled in EC/TEGDME-50/50+0.1 M LiNO 3 electrolyte:

a) C $1 \mathrm{~s}$ spectra, b) O $1 \mathrm{~s}$ spectra, c) N $1 \mathrm{~s}$ spectra and d) corresponding depth profiles showing a distribution of SEI components from the surface to the bulk. e) The Arrhenius behavior of the reciprocal and the activation energy $\left(E_{a}\right)$ derived for the ion diff usion through the SEI formed in diff erent electrolytes. The typical force curves obtained by AFM showing mechanical responses of SEI film generated in f) EC/EC/TEGDME-50/50, TEGDME+0.1 M LiNO 3 and g) EC/TEGDME-50/50+0.1 M LiNO3 electrolytes.

In the carbonate electrolyte system (EC/DMC/EMC), the SEI layer is mainly composed of carbonate and $\mathrm{Li}_{-}$alkyl carbonates $\left(\mathrm{Li} 2 \mathrm{CO}{ }_{3} / \mathrm{RC}-\right.$ O- $\underline{\mathrm{CO}}_{2} \mathrm{Li}$ ) as shown by high intensity of carbon peak at $\sim 289.6 \mathrm{eV}$ (Fig._S1). The presence of high quantity of carbonate and Li-alkyl carbon-ates on the surface of the negative electrode cycled in carbonate based electrolytes was already confirmed in numerous previous studies. $[31,32,42,43]$ When replaced by the pure TEGDME electrolyte, the lower quantity of carbonates and/or Li-alkyl carbonates can be observed, however, the increased quantity of species composed of -C-O-C-bonding can be clearly seen. Thus, it can be concluded that the SEI layer is principally composed of PEO $\left.\left(\mathrm{CH}_{2}-\mathrm{CH}_{2}-\mathrm{O}\right)_{\mathrm{n}^{-}}\right)$and/or $\mathrm{RC}-\underline{\mathbf{O}}-\mathrm{CO}_{2} \mathrm{Li}$ (Fig. S2).

After introducing $\mathrm{LiNO}_{3}$ additive into the TEGDME-containing electrolyte, the $\mathrm{N} 1 \mathrm{~s}$ peak can be clearly observed on the surface of the cycled Li electrode (Fig. S3). As it can be observed from sputtering with diff erent times corresponding to diff erent depths a relatively homogenous distribution of N-like components can be observed within the SEI layer (Fig. S3a-d). However, the TEGDME decomposition product as observed from high intensity of $\mathrm{C} 1 \mathrm{~s}$ and $\mathrm{O} 1 \mathrm{~s}$ peaks corresponding to $\mathrm{PEO}-\left(\mathrm{CH}_{2}-\mathrm{CH}_{2}-\mathrm{O}\right)_{\mathrm{n}}-$ is still significant, indicating that both TEGDME and $\mathrm{LiNO}_{3}$ participate in the formation of the SEI layer.

A relatively uniform in-depth distribution of the SEI layer can be also observed in the case of EC-only TEGDME electrolyte (EC/TEGDME50/50) (Fig. S3e-h). The presence of EC shows more important enrichment in carbonate and $\mathrm{Li}$-alkyl carbonates $\left(\mathrm{Li} 2 \mathrm{CO}_{3} / \mathrm{RC}-\mathrm{O}-\mathrm{CO} \mathrm{Li}\right)$ than it can be observed in the TEGDME-LiNO 3 electrolyte (Fig. S3a-d) and the presence of TEGDME related components is less obvious. It is worth noting by making a comparison of depth profiles obtained in diff erent electrolytes that the unique heterogeneous SEI structure can be observed in EC/TEGDME-50/50+0.1 $\mathrm{M} \mathrm{LiNO}_{3}$ electrolyte (Fig. 2d). As aforemontioned $\mathrm{LiNO}_{3}$ leads to formation of a $\mathrm{Li}_{\mathrm{X}} \mathrm{NO}_{\mathrm{y}}$ and/or $\mathrm{Li}_{3} \mathrm{~N}$ component on the $\mathrm{Li}$ anode (Fig. 2c); the content of $\mathrm{Li}_{\mathrm{X}} \mathrm{NO}_{\mathrm{y}}$ and/or $\mathrm{Li}_{3} \mathrm{~N}$ component gradually increases with sputtering depth (<24 $\mathrm{nm})$ and maintains sta-ble in the inner part of the SEI layer $(>24 \mathrm{~nm})$. The in-depth increase of $\mathrm{Li}_{\mathrm{X}} \mathrm{NO}_{\mathrm{y}}$ and/or $\mathrm{Li}_{3} \mathrm{~N}$ component is accompanied by the suppression of $\mathrm{C}$-species components. These results are consistent with the selective reduction of $\mathrm{LiNO}_{3}$ and $\mathrm{EC}$ due to their stepwise increase of LUMO energies.

The kinetics and structure of various SEIs formed in several electrolytes were studied through the electrochemical impedance spectra (EIS) of Li/Li symmetric batteries with a temperature range of 10 to $60{ }^{\circ} \mathrm{C}$ (Fig. S4). The activation energy ( $\left.E_{a}\right)$ for Li ion diff usion through SEI films can be calculated using the Arrhenius equation: $\mathrm{R}_{\mathrm{SEI}}{ }^{-1}=\operatorname{Aexp}\left(\stackrel{-\mathrm{E}}{\mathrm{R}} \cdot \mathrm{T}^{\mathrm{a}}\right)$. [26,44] A lower activation energy $\left(E_{a}\right)$ corresponds to faster kinetics of Li ion diff usion through the SEI film. This results in a larger Li ion concentration beneath SEI, which is a key factor for the generation of big Li particles instead of $\mathrm{Li}$ dendrites [26]. As one can observe from the Fig. $2 \mathrm{e}$, the $E_{a}$ of $\mathrm{Li}^{+}$ion diff usion through $\mathrm{SEI}$ film generated in EC/TEGDME-50/50 electrolyte is $60.8 \mathrm{~kJ} \mathrm{~mol}^{-1}$, while the $E_{a}$ of TEGDME+0.1 $\mathrm{M} \mathrm{LiNO}_{3}$ is $38.3 \mathrm{~kJ}$ mol ${ }^{-1}$. These results 
indicate that the $\mathrm{N}$-rich SEI film generated in $\mathrm{LiNO}_{3}$-contained electrolyte has a higher $\mathrm{Li}^{+}$ion conductivity. Consequently, a smaller $E_{a}$ $\left(47.1 \mathrm{~kJ} \mathrm{~mol}^{-1}\right.$ ) was observed in EC/TEGDME-50/50 with $\mathrm{LiNO}_{3}$ as additive, indicating a higher Li ion concentration beneath SEI, benefiting large Li particle formation.

In an eff ort to estimate the physical properties of SEI films formed in the target electrolyte, typical force curves showing mechanical responses of SEI films were measured using Atomic Force Microscope (AFM). To prevent the growth of Li dendrites, the SEI films generated on Li surface must to possess a high Yang's module (>1 GPa) [45]. A typical mechanical response of SEI film can be divided into two regions: elastic region and yield region (Fig. 2f). The Yang's module of SEI film can be obtained with data in the elastic region. [46,47] Yang's module of SEI film formed in TEGDME+0.1 M LiNO $3(1.87 \pm 0.12 \mathrm{GPa})$ is smaller than that formed in EC/TEGDME-50/50 ( $3.25 \pm 0.17 \mathrm{GPa})$, which may be a result of the large amount of stiff inorganic components $\left(\mathrm{Li}_{2} \mathrm{CO}_{3}, \mathrm{ROCO}_{2} \mathrm{Li}\right.$ etc.) generated by EC component. In contrast, the SEI film formed in EC/TEGDME-50/50+0.1 $\mathrm{M} \mathrm{LiNO}_{3}$ electrolyte displays a typical heterogeneous SEI structure, which corresponds well to the results revealed by XPS (Fig. $2 \mathrm{~g}$ ). The inner sub-layer SEI film with a thickness of $\sim 25.0 \mathrm{~nm}$, shows a Yang's module of approximately $2.02 \mathrm{GPa}$, associating well with the N-richness. However, in the outer C-rich sub-layer, a soft SEI film ( $0.32 \mathrm{GPa}$ ) with a thickness of $\sim 34.3 \mathrm{~nm}$ is detected. This unique soft-rigid heterogeneous SEI structure can collaborate well in regulating $\mathrm{Li}$ morphology and suppressing electrolyte decomposition.

To explain outer C-rich and inner $\mathrm{N}$-rich sub-layers of SEI on Li metal anode, we simulated the interactions between electrolyte molecules and Li metal surface by density functional theory (DFT) as shown in Fig. 3. Fig. 3a demonstrates that $\mathrm{LiNO}_{3}$ molecules undergone strongly chemical reaction with $\mathrm{Li}$ metal surface. The outer $\mathrm{Li}$-ions on $\mathrm{Li}$ metal surface enter the region of $\mathrm{LiNO}_{3}$ molecules and come into being amorphous form, and inner Li-ions within $\mathrm{Li}$ metal also undergo large displacement. However, Li metal surface with EC and TEGDME molecules can maintain stable molecular geometries and Li-metal configuration, indicating that there is no strong interaction between carbon-based molecules and $\mathrm{Li}$ metal. Thus, we hypothesized that inner $\mathrm{N}$-rich layer of $\mathrm{SEI}\left(\mathrm{Li}_{3} \mathrm{~N}, \mathrm{Li}_{\mathrm{x}} \mathrm{N}_{\mathrm{y}} \mathrm{O}_{\mathrm{Z}}\right.$ compounds) are more likely to contribute the high reactivity of $\mathrm{LiNO}_{3}$, which is easily reduced with $\mathrm{Li}$ metal.

(a) Initial configuration

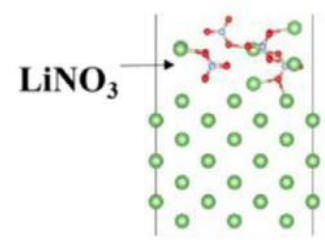

$\mathrm{Li}(100)-\mathrm{LiNO}_{3}$

EC

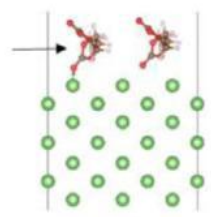

Li(100)-EC

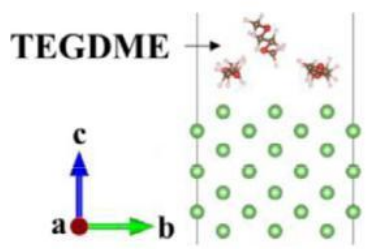

Li(100)-TEGDME
Final configuration

After relaxation

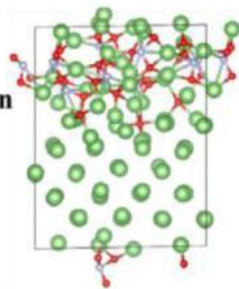

After relaxation

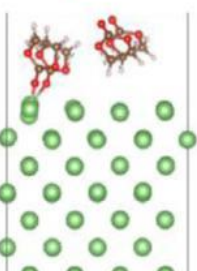

00000

After relaxation

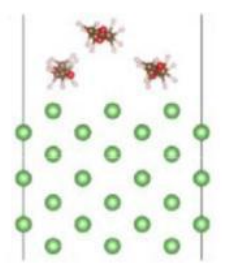

(b)

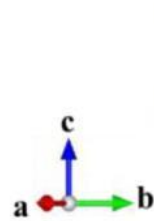

b

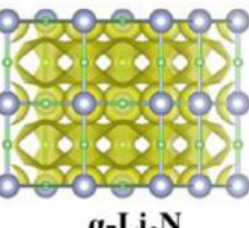

$\alpha-\mathrm{Li}_{3} \mathbf{N}$

cop-9posep

a 0 : 5

crich

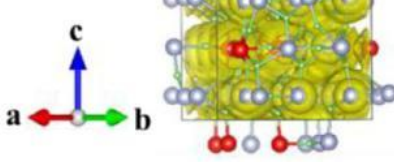

$\mathbf{L i}_{1.4} \mathbf{N}_{0.4} \mathbf{O}_{0.1}$

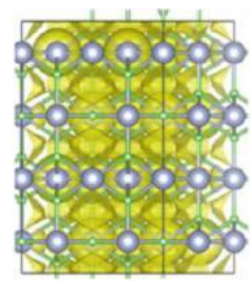

$\boldsymbol{\beta}-\mathbf{L i}_{3} \mathbf{N}$
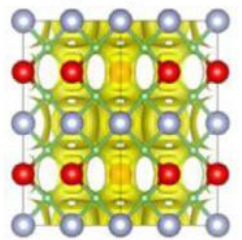

$\mathrm{Li}_{8} \mathrm{~N}_{3} \mathrm{O}, \mathrm{Li}_{8} \mathrm{NO}_{3}, \mathrm{Li}_{4} \mathrm{NO}$

(c)

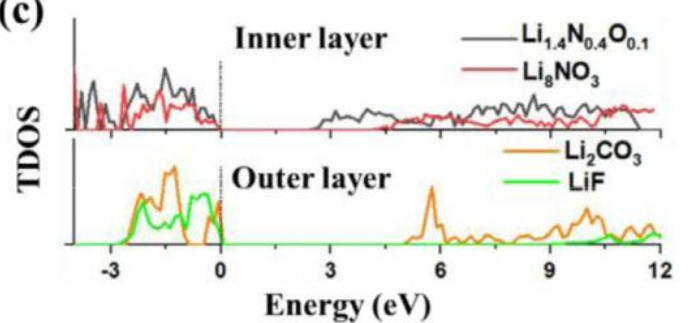


Fig. 3. Theoretical calculation of the SEI properties. a) The interactions of electrolytes and Li metal surface. The stability of electrolytes with Li metal was assessed by relaxing the configurations. The right insets suggested that $\mathrm{LiNO}_{3}$ molecules undergone strongly interfacial chemical reaction. However, Li metal surface with EC and TEGDME molecules maintain stable after relaxation. b) The potential diff usion pathway in $-\mathrm{Li}_{3} \mathrm{~N},-\mathrm{Li}_{3} \mathrm{~N}, \mathrm{Li}_{1.4} \mathrm{~N}_{0.4} \mathrm{O}_{0.1}$, and $\mathrm{Li}_{\mathrm{x}} \mathrm{N}_{\mathrm{y}} \mathrm{O}_{\mathrm{z}}$ ( $\mathrm{Li}_{8} \mathrm{NO}_{3}, \mathrm{Li}_{8} \mathrm{~N}_{3} \mathrm{O}$, and $\mathrm{Li}_{4} \mathrm{NO}$ belong to the same space group) illustrated by the bond valence mismatch method. Green, red, while, dark brown, and light blue spheres represent $\mathrm{Li}, \mathrm{O}, \mathrm{H}, \mathrm{C}$, and $\mathrm{N}$ atoms, respectively. c) The total density of states (TDOS) of $\mathrm{Li}_{1.4} \mathrm{~N}_{0.4} \mathrm{O}_{0.1}$ and $\mathrm{Li}_{8} \mathrm{NO}_{3}$. Energies are referenced to the Fermi level.

It has been accepted that Li-ion diff usion barrier governors the structure of the plated/striped surface, that is, the higher the diff usivity of the $\mathrm{Li}$ ions on SEI, the lower the tendency to form $\mathrm{Li}$ dendrites. We next checked the $\mathrm{Li}$-ion diff usivity in $-\mathrm{Li}_{3} \mathrm{~N},-\mathrm{Li}_{3} \mathrm{~N}, \mathrm{Li}_{1.4} \mathrm{~N}_{0.4} \mathrm{O}_{0.1}$, and $\mathrm{Li}_{\mathrm{X}} \mathrm{N}_{\mathrm{y}} \mathrm{O}_{\mathrm{Z}}$ compounds $\left(\mathrm{Li}_{8} \mathrm{NO}_{3}, \mathrm{Li}_{8} \mathrm{~N}_{3} \mathrm{O}\right.$, and $\mathrm{Li}_{4} \mathrm{NO}$ belong to the same

space group) by bond valence mismatch method as shown in Fig. 3b. All three configurations off er connected Li-ion diff usion channels and short $\mathrm{Li}-\mathrm{Li}$ distance. More importantly, $-\mathrm{Li}_{3} \mathrm{~N}$ and $-\mathrm{Li}_{3} \mathrm{~N}$ have been proven to be fast $\mathrm{Li}$-ion conductors and can suppress dendrite growth. In Fig. 3c, for the compounds of the inner shell of SEI film, such as $\mathrm{Li}_{1.4} \mathrm{~N}_{0.4} \mathrm{O}_{0.1}$ and $\mathrm{Li}_{8} \mathrm{NO}_{3}$, have narrow band gap ranging from 2.0 to 4.5 eV. For outer sub-layer of SEI film, such as $\mathrm{Li}_{2} \mathrm{CO}_{3}$ and $\mathrm{LiF}$, their band gap as large as 5.0 and $9.5 \mathrm{eV}$, respectively, indicate that they are good electron insulators to avoid the electrolyte components capture the electron and be reduced. Consequently, a heterogeneous SEI structure with high Li-ions conductivity in the inner shell while with electronic insulation in the outer shell is generated.

\subsection{Effect of heterogeneous SEI film on Li dendrites and Li loss}

The formation of Li dendrites is the one of the main challenges that threatens the practical application of Li metal batteries. To explore the eff ect of heterogeneous SEI film on Li dendrite formation and Li loss, scanning electron microscopy (SEM) was employed to visualize the evolution of $\mathrm{Li}$ metal after 30 cycles at a current density and $\mathrm{Li}$ capacity of $2.0 \mathrm{~mA} \mathrm{~cm}{ }^{-2}, 2.0 \mathrm{mAh} \mathrm{cm}^{-2}$ in diff erent electrolytes. In EC/DMC/EMC electrolyte, Li surface becomes porous and heterogenous after cycling with numerous filament-like Li growth (Fig. S5a) and the thickness of the porous Li layer is $\sim 53 \mathrm{~m}$ (Fig. S5b). The surface of Li foil cycled in the TEGDME electrolyte displays a nodule-like morphology and easily peels off during cycling, resulting a large quantity of dead Li formed on the separator (Fig. S5c, black color). The introduction of $\mathrm{LiNO}_{3}$ additive into TEGDME electrolyte shows a similar morphology compared with the bare one (Fig. 4a). However, the thickness of porous Li layer decreases from $136 \mathrm{~m}$ (Fig. S5d) to $60 \mathrm{~m}$ (Fig. 4b), showing the efficient film-forming additive, LiNO 3 , contributes to a compact $\mathrm{Li}$ deposition. However, the $\mathrm{LiNO}_{3}$-only TEGDME electrolyte cannot avoid the active Li loss during long-term cycling processes as evidenced by the presence of some dead Li deposited on the separator (inserted in Fig. 4b, black color). After replacing the electrolyte with EC/TEGDME-50/50, the Li surface exhibits a hybrid morphology with both filament-like and nodule-like Li growth (Fig. 4c), and the formation of dead Li on separator is eff ectively suppressed (inserted in Fig. 4c, black color)). The thickness of porous Li layer is reduced to only $38 \mathrm{~m}$ (Fig. 4d), proving that the mixture of EC and TEGDME aids in forming a tighter Li layer. Diff erently, big Li particles with brick-shape are obtained by the heterogeneous SEI film generated in EC/TEGDME-50/50+0.1 $\mathrm{M} \mathrm{LiNO}_{3}$ electrolyte. The Li surface here is much flatter than others, and there is no dead Li formed on the separator (Fig. 4e). Moreover, the thickness of porous Li layer is only $\sim 6 \mathrm{~m}$, embedded with packed Li-particles (Fig. 4f). The larger particle size of Li mitigates an internal short circuit and improve safety and reduces the parasitic interfacial reactions by decreasing the contact area between Li and electrolyte. It allows for a higher Li Coulombic efficiency and longer lifespan of Li metal anodes [48]. 

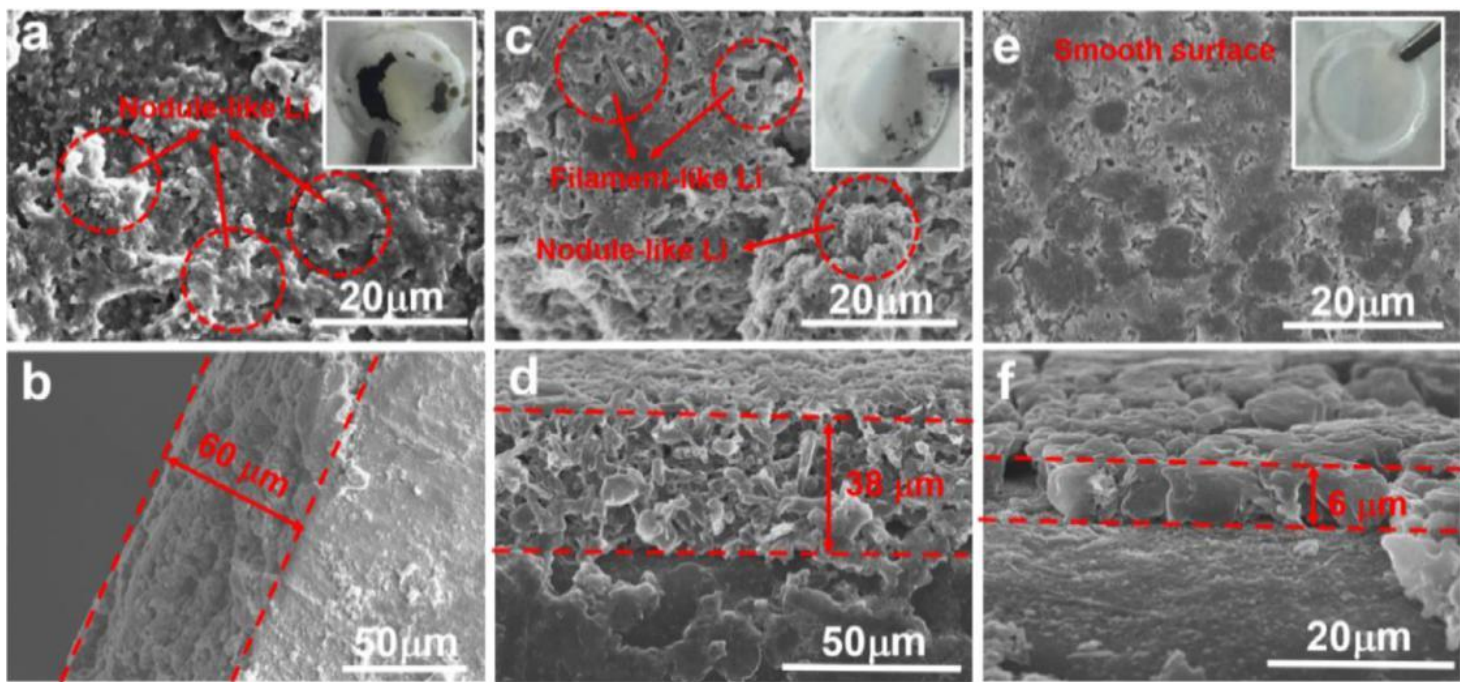

Fig. 4. Elucidation of the morphological evolution of lithium metal anodes. The SEM top- and side-view images of the Li foils cycled in diff erent electrolytes for

30 cycles at $2.0 \mathrm{~mA} \mathrm{~cm}^{-2}, 2.0 \mathrm{mAh} \mathrm{cm}^{-2}$ : a, b) TEGDME+0.1 $\left.\mathrm{M} \mathrm{LiNO}_{3}, \mathrm{c}, \mathrm{d}\right)$ EC/TEGDME-50/50, e, f) EC/TEGDME-50/50+0.1 M LiNO 3 . Corresponding optical photographs of separators after 30 cycles inserted in Figure. 4a, c, e.

\subsection{Effect of heterogeneous SEI film on Li/electrolyte interface}

We then attempted to identify the heterogeneous SEI structure and investigation of its electrochemical properties. Commercialized carbonate electrolyte exhibits a low average Li Coulombic efficiency of only $69.7 \%$ at $0.5 \mathrm{~mA} \mathrm{~cm}{ }^{-2}, 0.5 \mathrm{mAh} \mathrm{cm}^{-2}$ (Fig. S6), implying significant $\mathrm{Li}$ loss due to the severe corrosion between $\mathrm{Li}$ and electrolyte. The TEGDME electrolyte also suffers poor $\mathrm{Li}$ utilization and low $\mathrm{Li}$ coulombic efficiency of only $14.6 \%$ (Fig. S7). This is attributed to the Li loss caused by loose Li deposition. Poor Li performance in TEGDME electrolyte can be significantly enhanced by the addition of film-forming electrolyte components. The $\mathrm{Li} / \mathrm{Cu}$ cell in TEGDME+0.1 $\mathrm{M} \mathrm{LiNO}_{3}$ increase the Li coulombic efficiency to over 90\%, compared to efficiency of $14.6 \%$ us-ing a $\mathrm{LiNO}_{3}$-free TEGDME electrolyte (Fig. 5a). This improvement is a direct result of $\mathrm{LiNO}_{3}$ forming a relatively stable SEI film on the Li an-odes. However, deterioration of the $\mathrm{Li}$ performance in TEGDME+0.1 M LiNO 3 occurs after only 25 cycles due to the depletion of $\mathrm{LiNO}_{3}$ additive. According to the narrow band gap of $\mathrm{LiNO}_{3}$ reductive products, $\mathrm{Li}_{x} \mathrm{NO}_{\mathrm{y}}$, the fast degradation of $\mathrm{Li}$ CE in TEGDME+0.1 M LiNO 3 can be ascribed to the electronic conductive SEI film cannot prohibit the constant electrolyte consumption. A feasible solution is to introduce EC as co-solvent to form a passive outer layer which stabilizes the Li electrolyte inter-face. We study the systematic results on the role of EC/TEGDME ratio in the electrochemical performance. A volumetric percentage increase of EC also increases the ionic conductivity of electrolyte from $2.84 \mathrm{mS} \mathrm{cm}^{-1}$ (10 Vol\% EC) to $6.21 \mathrm{mS} \mathrm{cm}^{-1}$ (60 Vol\% EC) (Fig. S8). Further in-creasing the percentage of EC to 70 Vol\% prevents the electrolyte from maintaining liquid status (Fig. S9). Improvement in ionic conductivity of electrolytes with diff erent amount of EC components can be explained by a lower viscosity and strong solvation eff ect of EC. As we can observe from Fig. S10, the TEGDME electrolyte displays a viscosity of $15 \mathrm{mPa}$, which decreases to $11.3 \mathrm{mPa}$ s after introducing 50 Vol.\% EC. A less viscous electrolyte decreases the transfer resistance of Li ions. This enables a higher ionic conductivity and faster charge-discharge processes in full cells. We conclude that the optimum EC volume percentage is 50\%, which results in a Li Coulombic efficiency of 97.5\% (Fig. 5a and Fig. S11). The EC/TEGDME-50/50 electrolyte alone, is still far from satisfying the requirements in a practical battery system. Combining EC and $\mathrm{LiNO}_{3}$ in TEGDME-based electrolyte elevates the Li Coulombic efficiency. An enhanced Li average coulombic efficiency of $99.0 \%$ for 
200 cycles at $0.5 \mathrm{~mA} \mathrm{~cm}^{-2}, 0.5 \mathrm{mAh} \mathrm{cm}^{-2}$ was achieved with further $0.1 \mathrm{M} \mathrm{LiNO}_{3}$ addition (Fig. 5b), indicating the heterogeneous SEI structure is eff ective in stabilizing $\mathrm{Li}$ electrolyte interface. The superior performance of EC/TEGDME-50/50+0.1 $\mathrm{M} \mathrm{LiNO}_{3}$ electrolyte was observed under higher current density and $\mathrm{Li}$ capacity cycled for each cycle. For in-stance, $98.1 \%$ at $1.0 \mathrm{~mA} \mathrm{~cm}^{-2}, 3.0 \mathrm{mAh} \mathrm{cm}^{-2} \mathrm{Fig} .5 \mathrm{c}$ ), $98.2 \%$ at $3.0 \mathrm{~mA} \mathrm{~cm}^{-2}, 3.0 \mathrm{mAh} \mathrm{cm}^{-2}$ (Fig. 5d) and $97.2 \%$ at $3.0 \mathrm{~mA} \mathrm{~cm}^{-2}, 3.0 \mathrm{mAh} \mathrm{cm}^{-2}$ (Fig. 5e).
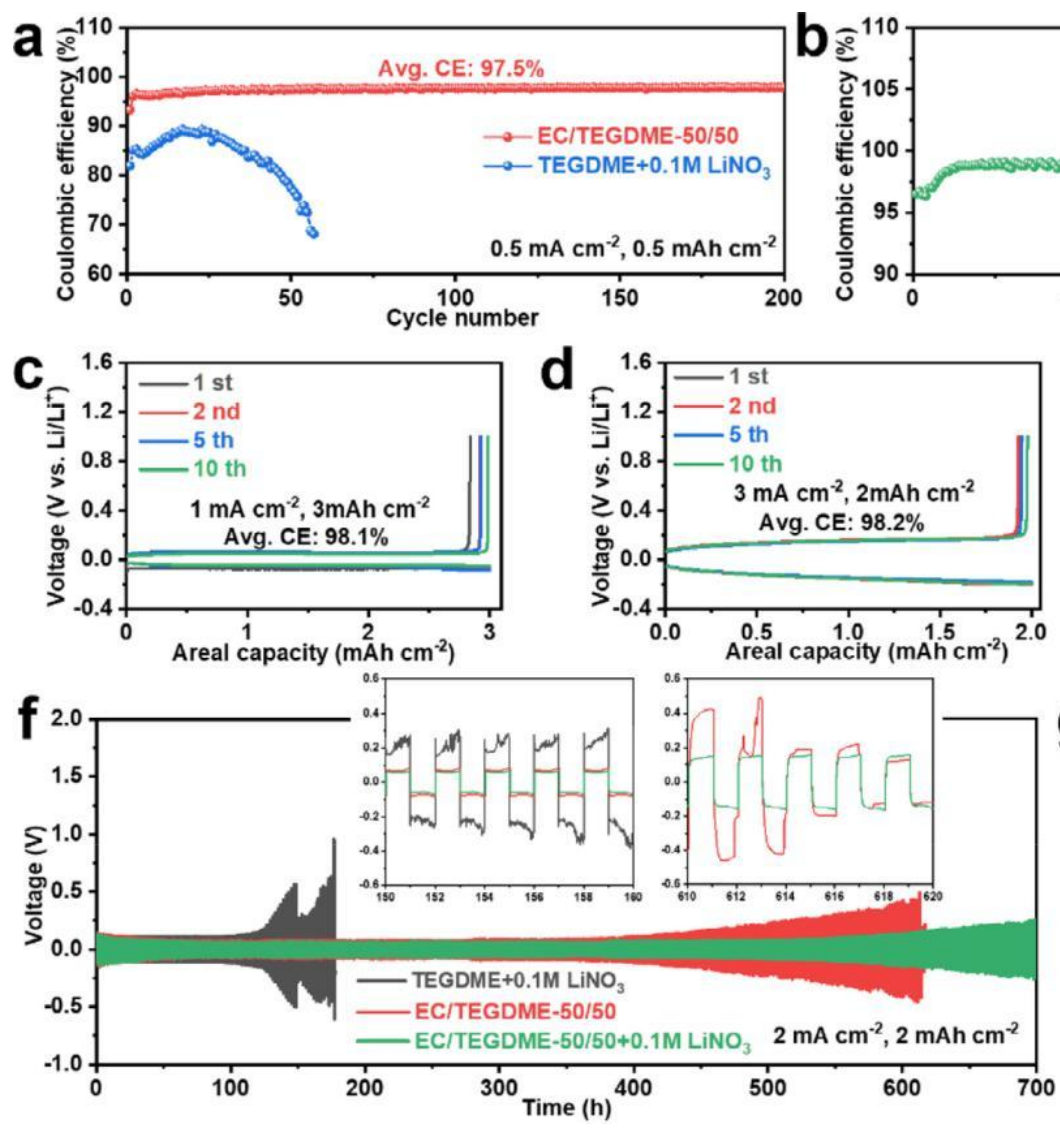
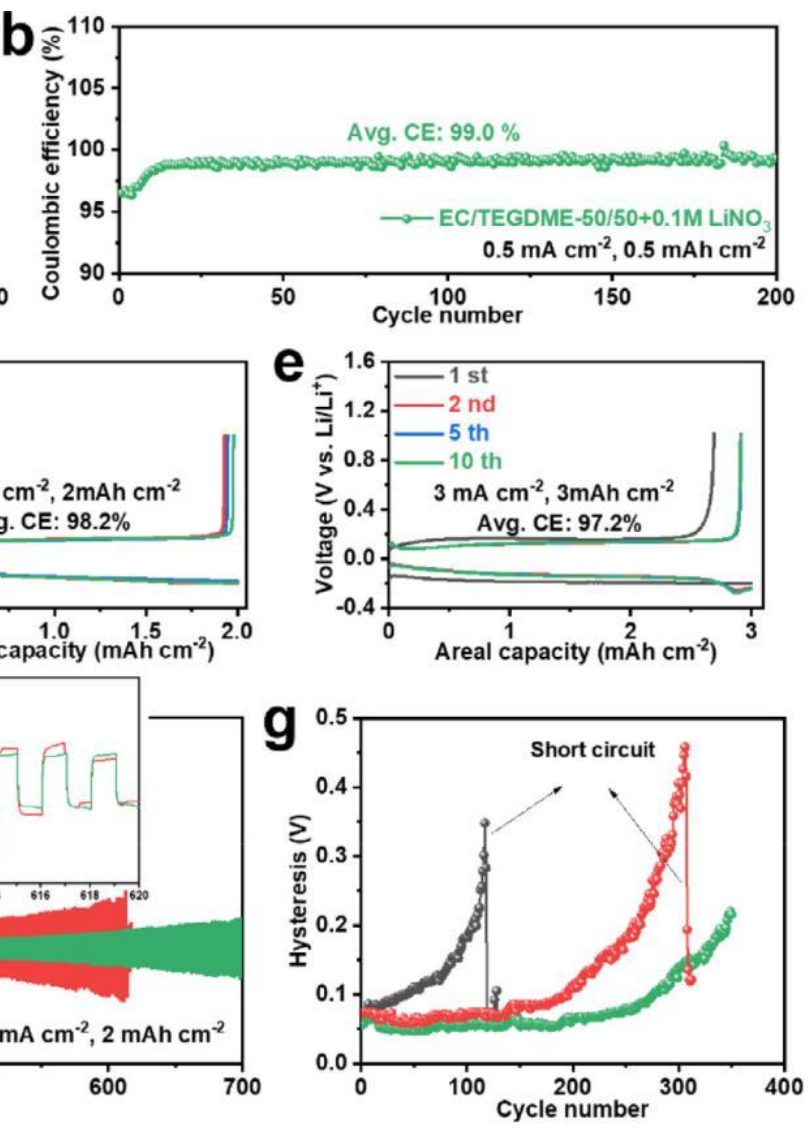

Fig. 5. Coulombic efficiency and cycling stability of lithium metal anodes. Li Coulombic efficiency of Li/Cu half-cells with diff erent electrolytes at $0.5 \mathrm{~mA}$ $\mathrm{cm}^{-2}, 0.5 \mathrm{mAh} \mathrm{cm}^{-2}$ : a) EC/TEGDME-50/50 and TEGDME+0.1 $\mathrm{M} \mathrm{LiNO}_{3}$, b) EC/TEGDME-50/50+0.1 $\mathrm{M} \mathrm{LiNO}_{3}$. The typical charge/discharge curves of Li/Cu half-cells with EC/TEGDME-50/50+0.1 $\mathrm{M} \mathrm{LiNO}_{3}$ electrolyte at diff erent conditions: c) $1.0 \mathrm{~mA} \mathrm{~cm}^{-2}, 3.0 \mathrm{mAh} \mathrm{cm}^{-2}$, d) $3.0 \mathrm{~mA} \mathrm{~cm}^{-2}, 2.0 \mathrm{mAh} \mathrm{cm}^{-2}$, e) $3.0 \mathrm{~mA} \mathrm{~cm}^{-2}, 3.0 \mathrm{mAh} \mathrm{cm}^{-2}$. f) The voltage-time curves and g) corresponding voltage hysteresis of the symmetric Li/Li cells with diff erent electrolytes at 2 $\mathrm{mA} \mathrm{cm}^{-2}, 2 \mathrm{mAh} \mathrm{cm}^{-2}$.

The long-term stability of the Li electrolyte interface was compared to the voltage-time profiles of symmetric Li/Li cells. As shown in Fig. S12, instability of the Li electrolyte interface in TEGDME electrolyte revealed an initial voltage hysteresis of $225 \mathrm{mV}$, which significantly deteriorated to $3.9 \mathrm{~V}$ after only 40 cycles. In contrast, a similar initial volt-age hysteresis of about $70 \mathrm{mV}$ was measured with diff erent electrolytes (Fig. 5f) at $2.0 \mathrm{~mA} \mathrm{~cm}^{-2}, 2.0 \mathrm{mAh} \mathrm{cm}{ }^{-2}$. Gradual increase followed by sudden subsequent drop in voltage was observed after 120 cycles in TEGDME+0.1 $\mathrm{M} \mathrm{LiNO}_{3}$ electrolyte and 300 cycles in EC/TEGDME-50/50 (Fig. 5g), corresponding an internal short circuit of the cells [49]. On the contrary, the EC/TEGDME-50/50+0.1 M LiNO 3 electrolyte delivers a lower hysteresis without short circuiting after 300 cycles $(600 \mathrm{~h})$, proving the heterogeneous SEI film can efficiently suppress the electrolyte decomposition and stabilize the $\mathrm{Li}$ electrolyte interface. In addition, the rate performance of $\mathrm{Li} / \mathrm{Li}$ symmetric cells also compared in Fig. S13. The cell with EC/DMC/EMC exhibits high polarization and in-crease sharply with the current densities enhanced, while the cell with EC/TEGDME-50/50 $+0.1 \mathrm{M} \mathrm{LiNO}_{3}$ delivers slowly elevation in over-potential with the current densities increase, indicating an excellent rate performance of Li 
anodes. Furthermore, short circuit occurs at $3 \mathrm{~mA} \mathrm{~cm}^{-2}$ for Li/Li cell with EC/DMC/EMC reveals the uncontrollable dendrite growth in EC/DMC/EMC electrolyte.

\subsection{High-cyclability and high-voltage Li metal batteries}

After identifying the optimum electrolyte composition, its electro-chemical performance in both coin cells and pouch cells with commercial cathodes $\left(\mathrm{LiCoO}_{2}, \mathrm{LCO}\right)$ and a thin $\mathrm{Li}$ foil $(25$ or $200 \mathrm{~m})$ were studied. We first investigated thee cyclability $\mathrm{LCO} / \mathrm{Li}$ coin cells (loading: $19.64 \mathrm{mg} \mathrm{cm}^{-2} / 3 \mathrm{mAh} \mathrm{cm}^{-2}$, Li: $200 \mathrm{~m}$, operating voltage region: $2.8-4.25 \mathrm{~V}$ ) in diff erent electrolytes at $0.2 \mathrm{C}$ and $0.5 \mathrm{C}$. In the bare TEGDME electrolyte, the specific capacity of LCO/Li cell drops to less than $25 \mathrm{mAh} g^{-1}$ after only 10 cycles at $0.2 \mathrm{C}$ (Fig. S14). Simi-lar degradation also occurs on the LCO/Li cells with commercial electrolyte (EC/DMC/EMC) (Fig. S14), a result of the large amount of dead Li formation during cycling. As shown in Fig. S15, LiNO3-only TEGDME (TEGDME+0.1 M LiNO 3 ) electrolyte exhibits an improvement in cycling performance over the bare TEGDME electrolyte, but still suff ers rapid capacity decay in the following cycles. The lifespan of the LCO/Li coin cells with an EC-only TEGDME electrolyte (EC/TEGDME-50/50) can be enhanced to 106 cycles at $0.2 \mathrm{C}$ and 75 cycles at $0.5 \mathrm{C}$ with a $80 \%$ ca-pacity retention, demonstrating that EC can generate efficient passive layer to deter the formation of dead Li (Fig. S15 and S16). The het-erogenous SEI film derived through EC/TEGDME-50/50+0.1 $\mathrm{M} \mathrm{LiNO}_{3}$ dramatically improves the cycling stability of the $\mathrm{LCO} / \mathrm{Li}$ cell. This cell can deliver an initial capacity of $158.2 \mathrm{mAh} \mathrm{g}^{-1}\left(3.1 \mathrm{mAh} \mathrm{cm}^{-2}\right)$, and $138.6 \mathrm{mAh}^{-1}$ after 130 cycles at $0.2 \mathrm{C}$, corresponding to a capacity retention of $87.6 \%$ (Fig. S15). Similarly, a desirable capacity retention of $86.1 \%$ after 100 cycles can be achieved at $0.5 \mathrm{C}$ (Fig. S16). The eff ect of $\mathrm{LiNO}_{3}$ concentration in EC/TEGDME-50/50 electrolytes was further investigated. As we can see from Fig. S17, low concentration of $\mathrm{LiNO}_{3}(0.05 \mathrm{M})$ delivers a relatively low $\mathrm{Li} \mathrm{CE}(\sim 98 \%)$ than that with $0.1 \mathrm{M} \mathrm{LiNO}_{3}(\sim 99 \%)$, while exhibits no obvious elevation at high concentration of $\mathrm{LiNO}_{3}(0.5 \mathrm{M})$. However, the cycling performance of $\mathrm{LCO} / \mathrm{Li}$ cells with highconcentration $\mathrm{LiNO}_{3}$ electrolyte (EC/TEGDME-50/50+0.5 $\mathrm{M} \mathrm{LiNO}_{3}$ ) would cause the declination of lifespan to only around 60 cycles (Fig. S18), which indicates the negative impact of $\mathrm{LiNO}_{3}$ on cathode interface at high concentration, meaning the $0.1 \mathrm{M} \mathrm{LiNO}_{3}$ can be suitable concentration for the LMBs.

To achieve a higher energy density than traditional LIBs, the cell requires the combination of high-areal-capacity cathodes $(>2.5 \mathrm{mAh}$ $\mathrm{cm}^{-2}$ ) and ultra-thin $\mathrm{Li}$ foils $(<60 \mathrm{~m})$. Hence, cathodes were fabricated by casting $\mathrm{LiCoO}_{2}$ on both sides of $\mathrm{Al}$ foils with an areal capacity of $3 \mathrm{mAh} \mathrm{cm}^{-2}$ for each side, and two pieces of ultra-thin Li chips with a thickness of only $25 \mathrm{~m}$ were employed as anodes, corresponding to a low N/P (negative/positive capacity) ratio of 1.67, (Fig. 6a). As the performance shown in Fig. 6b, the pouch cells with this configuration were fabricated with a initial capacity of $150 \mathrm{mAh}$ in total. An unprecedented capacity retention of $91.6 \%$ after 160 cycles was achieved with EC/TEGDME-50/50+0.1 $\mathrm{M} \mathrm{LiNO}_{3}$ as electrolyte, which demonstrates the promising practical application of the target electrolyte.

The linear sweep voltammetry (LSV) curves suggest that the TEGDME can achieve a stable anodic potential as high as $4.8 \mathrm{~V}$, and only slightly decrease to $4.5 \mathrm{~V}$ after introducing $50 \mathrm{Vol}$ \% EC, indicating the potential of utilizing EC/TEGDME-50/50 electrolyte in high-voltage battery systems. Further $\mathrm{LiNO}_{3}$ addition would not aff ect the stable potential window of electrolyte, which also enbales the operation at 4.5 $\mathrm{V}$ (Fig. S19). To further evaluate the anti-oxidation property of the optimum electrolyte, high-loading $\left(\sim 13 \mathrm{mg} \mathrm{cm}^{-2}, \sim 2.5 \mathrm{mAh} \mathrm{cm}^{-2}\right)$ $\mathrm{LiCoO}_{2}$ cathodes were matched with thin $\mathrm{Li}$ foils $(200 \mathrm{~m}$ ) to assemble the $\mathrm{LCO} / \mathrm{Li}$ coin cells, which underwent an elevated charging voltage of $4.5 \mathrm{~V}$ (Fig. $6 \mathrm{c}$ and d). Herein, $1 \mathrm{C}$ is defined as $180 \mathrm{~mA} \mathrm{~g}{ }^{-1}$. The cell cycled in TEGDME+0.1 $\mathrm{M} \mathrm{LiNO}_{3}$ electrolyte had a high initial capacity of $187.9 \mathrm{mAh}^{-1}\left(2.44 \mathrm{mAh} \mathrm{cm}^{-2}\right)$ but suff ers a sharp capacity decay in the following cycles. From the corresponding chargedischarge curves we can know that the polarization of the cells significantly increase after 20 cycles, associating a destructive capacity degradation, and only left $\sim 20 \mathrm{mAh}{ }^{-1}$ after 30 cycles (Fig. 6e). With the EC/TEGDME-50/50 electrolyte, LCO/Li coin cells achieve 148 cycles and 157 cycles at $0.2 \mathrm{C}$ and $0.5 \mathrm{C}$, respectively. An excellent cycling performance was obtained in EC/TEGDME-50/50+0.1 M 
$\mathrm{LiNO}_{3}$ with a capacity retention of $91.5 \%$ after 180 cycles at $0.2 \mathrm{C}$ (Fig. 6c). At higher current rate (0.5C), a remarkable long-term cycling performance over 300 cycles with a capacity retention of $85.7 \%$ is possible when using EC/TEGDME-50/50+0.1 M LiNO3 electrolyte (Fig. 6d). As revealed in Fig. 6f and g, the LCO/Li cell cycled in EC/TEGDME-50/50+0.1 $\mathrm{M} \mathrm{LiNO}_{3}$ displays smaller polarization and less capacity decay than that cycled in EC/TEGDME-50/50. And even after 300 cycles, there is only slight increase in polarization, indicating the desirable heterogenous SEI structure significantly stabilize the Li interface. Additionally, the rate capability of LCO/Li cells with diff erent electrolytes was compared (Fig. S20). For the commercial EC/DMC/EMC electrolyte, the LCO/Li cell delivers a poor rate performance with nearly $0 \mathrm{mAh} \mathrm{cm}{ }^{-2}$ at $3 \mathrm{C}$, which results from the poor performance of $\mathrm{Li}$ anodes. Thus, to eliminate the influence of Li anodes, the EC/DMC/EMC electrolyte with 5\% FEC as additive was applied to evaluate the real rate capability of commercial electrolyte. Significantly, $\mathrm{EC} / \mathrm{DMC} / \mathrm{EMC}$ with $5 \% \mathrm{FEC}$ can deliver an excellent rate capability with $\sim 2 \mathrm{mAh} \mathrm{cm}^{-2}$ at $3 \mathrm{C}$ rate. Owing to the relatively higher viscosity of TEGDME-based electrolyte, EC/TEGDME-50/50+0.1 M LiNO3 delivers a relatively poor performance at high rate (3 C). However, EC/TEGDME-50/50+0.1 $\mathrm{M} \mathrm{LiNO}_{3}$ also can perform a similar capacity at $2 \mathrm{C}$ compared with EC/DMC/EMC with 5\% FEC, which can satisfy the practical application.

The evolution of SEI properties in full cells can be monitored by in-situ EIS. Herein, a three-electrodes pouch cell with LCO as work electrode, $\mathrm{Li}$ foil as counter electrode, and $\mathrm{Li}$ wire as reference electrode was adopted to avoid the eff ect of cathode resistance on the anode. Fig. S21 reveals the evolution of resistance of $\mathrm{Li}$ anodes during a whole charge-discharge cycle in $\mathrm{LCO} / \mathrm{Li}$ cells in EC/DMC/EMC and EC/TEGDME-50/50+0.1 M LiNO 3 . The Nyquist plots were further fitting analysis according the equivalent circuit model shown in Fig. S22. For the EC/DMC/EMC electrolytes, the $\mathrm{R}_{\mathrm{SEI}}$ decrease during the charging process, which results from the porous Li deposition enlarge the surface area of anodes. While RSEI further significantly increase in following discharging process, accompanied with improvement of $\mathrm{R}_{c t}$, which means the thick SEI generation significantly enhances the resistance of SEI film and retard the charge transfer processes. On the contrary, the Li anodes cycled in EC/TEGDME-50/50+0.1 M LiNO 3 delivers a relatively small and stable SEI resistance during the whole charging/discharging process. Meanwhile, low $\mathrm{R}_{c t}$ also are delivered in EC/TEGDME-50/50+0.1 $\mathrm{M}$ LiNO 3 , indicating the a stable and fast ionic conductive SEI was generated by EC/TEGDME/LiNO 3 electrolyte system.
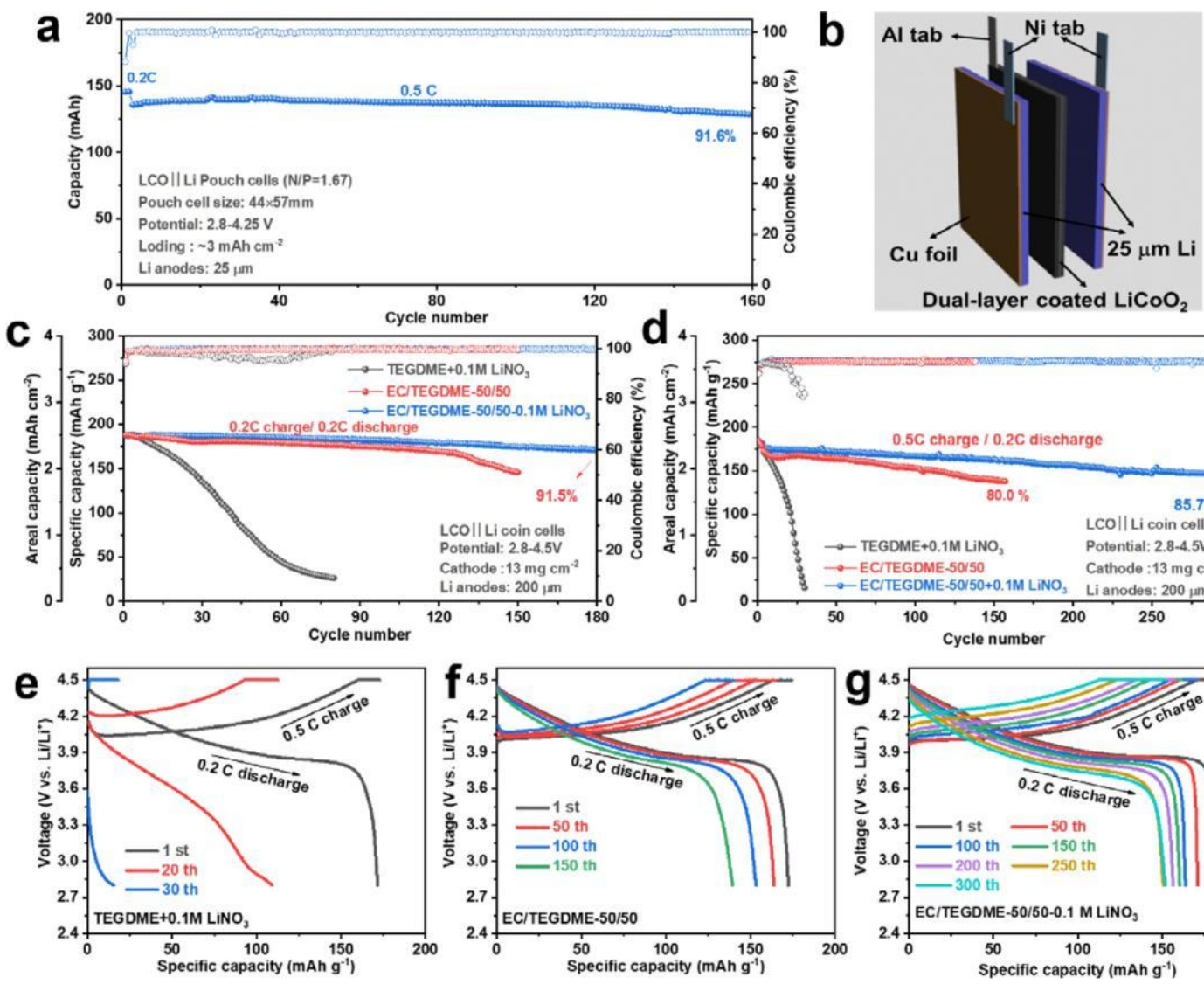

Dual-layer coated $\mathrm{LiCoO}_{2}$
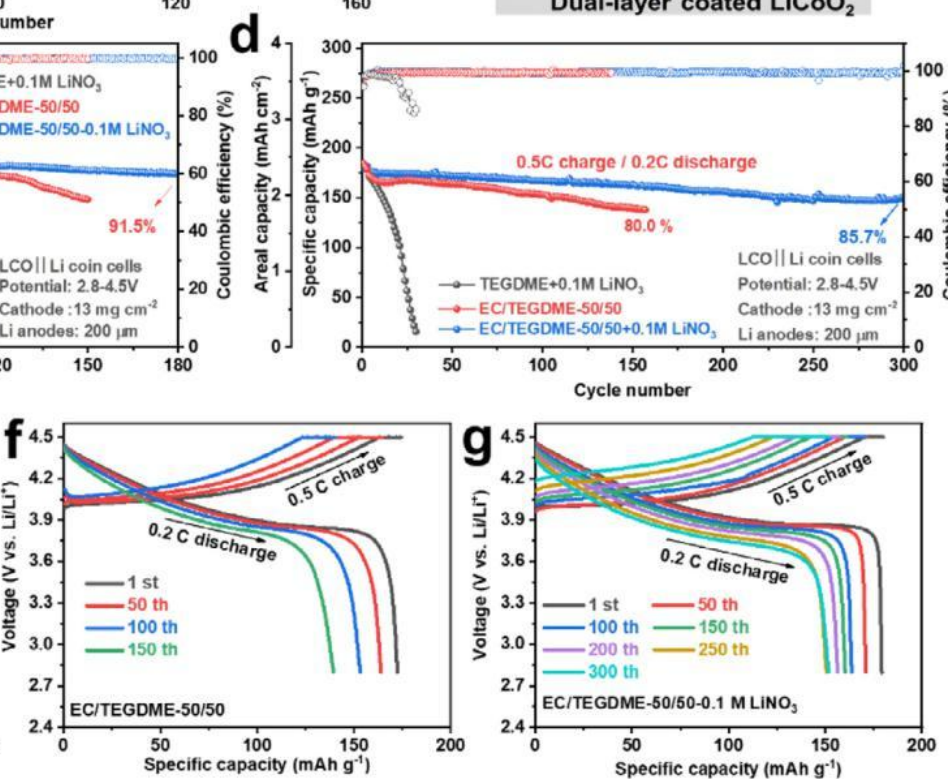
Fig. 6. Electrochemical performance under practically relevant conditions. a) The structure of pouch cells and b) Cycling performance of the pouch cell with ultra-thin $\mathrm{Li}$ foil $(25 \mathrm{~m})$. The cycling performance of the $\mathrm{LiCoO}_{2} / \mathrm{Li}$ coin cells with diff erent electrolytes at c) $0.2 \mathrm{C}$ and (d) $0.5 \mathrm{C}$ at a cut-off voltage range of 2.8-4.5 V. The typical charge-discharge curves of the $4.5 \mathrm{~V} \mathrm{LCO/Li} \mathrm{cells} \mathrm{in} \mathrm{diff} \mathrm{erent} \mathrm{electrolytes:} \mathrm{e)} \mathrm{TEGDME+0.1} \mathrm{M} \mathrm{LiNO} 3$, f) EC/TEGDEM-50/50 and g) EC/TEGDME-50/50+0.1 $\mathrm{M} \mathrm{LiNO}_{3}$

\section{Conclusions}

A novel and straightforward method to directionally design het-erogenous SEI with inner-outer hybrid electronic/ionic conductivity via selective reduction of electrolyte components is found to be capable of achieving both high Li utilization and high oxidation tolerance for Li metal battery. TEGDME-based electrolyte suff ers poor performance on Li metal anodes, resulting in the constant decomposition of TEGDME by Li metal. $\mathrm{LiNO}_{3}$ efficiently stabilizes the Li electrolyte interface; how-ever, the batteries still suff er sharp degradation with the consumption of $\mathrm{LiNO}_{3}$. Introducing $50 \mathrm{Vol} \%$ EC to replace part of the TEGDME in electrolyte significantly suppresses the exhaustion of $\mathrm{LiNO}_{3}$ additive. Consequently, a remarkable Li coulombic efficiency of $99.0 \%$ is attained using EC/TEGDME-50/50+0.1 M LiNO 3 . DFT calculations and XPS depth analysis demonstrate that the $\mathrm{LiNO}_{3}$ is reduced by $\mathrm{Li}$ metal prior to the EC. A heterogenous SEI film with an outer C-rich region and an inner N-rich region is generated on the $\mathrm{Li}$ surface. In the film, the inner region exhibits high Li ${ }^{+}$conductivity, leading to the round-shape $\mathrm{Li}$ de-position, while the outer region with electronic insulation serves as a passive layer delivering less electrolyte consumption. The AFM SEI film study verified the formation of the heterogenous SEI structure and their physical properties, consisting of an inner rigid region $(\sim 2.02 \mathrm{GPa})$ and outer soft region $(\sim 0.32 \mathrm{GPa})$. Benefiting from this novel heterogenous SEI structure, the morphology of Li metal becomes nodule-like and the thickness of the porous Li layer after cycling was only $6 \mathrm{~m}$, which is significantly thinner than that in bare TEGDME electrolyte $(136 \mathrm{~m})$. The LCO/Li full cells were also studied for the practical application of EC/TEGDME-55+0.1 $\mathrm{M} \mathrm{LiNO}_{3}$ with excellent results. Pouch cells with ultra-high-loading $\left(3 \mathrm{mAh} \mathrm{cm}^{-2}\right) \mathrm{LiCoO}_{2}$ electrodes and ultra-thin Li foils $(25 \mathrm{~m})$ deliver an outstanding cycling performance with a capacity retention of $91.6 \%$ after 160 cycles. The high-voltage LCO/Li $(4.5 \mathrm{~V})$ batteries with modified configuration deliver an $85.7 \%$ capacity retention after 300 cycles, demonstrating superb Li utilization and high voltage tolerance of electrolytes. This approach can be considered as a suitable strategy to generate a desirable SEI structure on the Li surface to achieve rechargeable Li metal batteries, which would be compatible with most of the existing Li battery systems in the pursuit of high energy densities.

\section{Acknowledgements}

This research work was supported by National Natural Science Foundation of China (Grant No. 21875197). University of Waterloo, the Natural Science and Engineering Research Council of Canada and the National Natural Science Foundation of China (Grant Nos. U1909213, 21625304 and 21733012).

\section{Supplementary material}

Supplementary date associated with this article is available.

\section{References}


[2] X. Gao, Y. Chen, L.R. Johnson, Z.P. Jovanov, P.G. Bruce, Nat. Energy. 2 (2017) 17118.

[3] H. Kim, G. Jeong, Y.U. Kim, J.H. Kim, C.M. Park, H.J. Sohn, Chem. Soc. Rev. 42 (2013) 9011-9034.

[4] Q. Xu, J. Lin, C. Ye, X. Jin, D. Ye, Y. Lu, G. Zhou, Y. Qiu, W. Li, Adv. Energy Mater. 10 (2019) 1903292.

[5] K. Liao, S. Wu, X. Mu, Q. Lu, M. Han, P. He, Z. Shao, H. Zhou, Adv. Mater. 30 (2018) 1705711.

[6] M. Bai, K. Xie, K. Yuan, K. Zhang, N. Li, C. Shen, Y. Lai, R. Vajtai, P. Ajayan, B. Wei, Adv. Mater. (2018) 1801213.

[7] E.K. Jang, J. Ahn, S. Yoon, K.Y. Cho, Adv. Funct. Mater. 29 (2019) 1905078.

[8] Y.T. Weng, H.W. Liu, A. Pei, F. Shi, H. Wang, C.Y. Lin, S.S. Huang, L.Y. Su, J.P. Hsu, C.C. Fang, Y. Cui, N.L. Wu, Nat. Commun. 10 (2019) 5824

[9] S.J. Zhang, Z.G. Gao, W.W. Wang, Y.Q. Lu, Y.P. Deng, J.H. You, J.T. Li, Y. Zhou,

L. Huang, X.D. Zhou, S.G. Sun, Small 14 (2018) 1801054.

[10] S. Liu, X. Xia, Y. Zhong, S. Deng, Z. Yao, L. Zhang, X.B. Cheng, X. Wang, Q. Zhang,

J. Tu, Adv. Energy Mater. 8 (2018) 1702322

[11] H. Shi, C.J. Zhang, P. Lu, Y. Dong, P. Wen, Z.S. Wu, ACS Nano 13 (2019) 14308-14318

[12] C. Sun, A. Lin, W. Li, J. Jin, Y. Sun, J. Yang, Z. Wen, Adv. Energy Mater. (2019) 1902989.

[13] Q. Xu, X. Yang, M. Rao, D. Lin, K. Yan, R. Du, J. Xu, Y. Zhang, D. Ye, S. Yang, G. Zhou, Y. Lu, Y. Qiu, Energy Stor. Mater. 26 (2020) 73-82.

[14] Z. Peng, X. Cao, P. Gao, H. Jia, X. Ren, S. Roy, Z. Li, Y. Zhu, W. Xie, D. Liu, Q. Li, D. Wang, W. Xu, J.G. Zhang, Adv. Funct. Mater. 30 (2020) 1606422.

[15] X. Cao, X. Ren, L. Zou, M.H. Engelhard, W. Huang, H. Wang, B.E. Matthews, H. Lee, C. Niu, B.W. Arey, Y. Cui, C. Wang, J. Xiao, J. Liu, W. Xu, J.G. Zhang, Nat. Energy. 4 (2019) 796-805.

[16] T. Jiang, P. He, G. Wang, Y. Shen, C.W. Nan, L.Z. Fan, Adv. Energy Mater. 10 (2020) 1903376.

[17] L. Chen, Y. Li, S.P. Li, L.Z. Fan, C.W. Nan, J.B. Goodenough, Nano Energy 46 (2018) 176-184.

[18] J. Hu, P. He, B. Zhang, B. Wang, L.Z. Fan, Energy Stor. Mater. 26 (2020) 283-289.

[19] L. Chen, W. Li, L.Z. Fan, C.W. Nan, Q. Zhang, Adv. Fuct. Mater. 29 (2019) 1901047.

[20] J. Qian, W.A. Henderson, W. Xu, P. Bhattacharya, M. Engelhard, O. Borodin, J.G. Zhang, Nat. Commun. 6 (2015) 6362

[21] X. Dong, Y. Lin, P. Li, Y. Ma, J. Huang, D. Bin, Y. Wang, Y. Qi, Y. Xia, Angew. Chem. Int. Ed. Engl. 58 (2019) $5623-5627$.

[22] X. Shangguan, G. Xu, Z. Cui, Q. Wang, X. Du, K. Chen, S. Huang, G. Jia, F. Li, X. Wang,

D. Lu, S. Dong, G. Cui, Small. 15 (2019) 1900269.

[23] P. Shi, L. Zhang, H. Xiang, X. Liang, Y. Sun, W. Xu, ACS Appl. Mater. Interfaces 10 (2018) 22201-22209.

[24] J. Zheng, M.H. Engelhard, D. Mei, S. Jiao, B.J. Polzin, J.G. Zhang, W. Xu, Nat. Energy 2 (2017) 17012.

[25] H. Ye, Y.X. Yin, S.F. Zhang, Y. Shi, L. Liu, X.X. Zeng, R. Wen, Y.G. Guo, L.J. Wan, Nano Energy 36 (2017) $411-417$. 
[26] X.R. Chen, Y.X. Yao, C. Yan, R. Zhang, X.B. Cheng, Q. Zhang, Angew. Chem. Int. Ed. Engl. 132 (2020) 7817-7821.

[27] J. Fu, X. Ji, J. Chen, L. Chen, X. Fan, D. Mu, C. Wang, Angew. Chem. Int. Ed. 59 (2020) 22194-22201.

[28] Y.X. Lin, Z. Liu, K. Leung, L.Q. Chen, P. Lu, Y. Qi, J. Power Sources 309 (2016) 221-230.

[29] C.C. Su, M. He, R. Amine, Z. Chen, R. Sahore, N.D. Rago, K. Amine, Energy Stor. Mater. 17 (2019) 284-292.

[30] J. Heine, P. Hilbig, X. Qi, P. Niehoff, M. Winter, P. Bieker, J. Electrochem. Soc. 162 (2015) A1094-A1101.

[31] C. Pereira-Nabais, J. Światowska, A. Chagnes, F. Ozanam, A. Gohier, P. Tran-Van, C.-.S. Cojocaru, M. Cassir, P. Marcus, Appl. Surface Sci. 266 (2013) 5-16.

[32] J. Światowska, V. Lair, C. Pereira-Nabais, G. Cote, P. Marcus, A. Chagnes, Appl. Surface Sci. 257 (2011) 9110-9119.

[33] M. Carboni, A.G. Marrani, R. Spezia, S. Brutti, J. Electrochem. Soc. 165 (2018) A118-A125.

[34] J. Zheng, P. Yan, D. Mei, M.H. Engelhard, S.S. Cartmell, B.J. Polzin, C. Wang, J.G. Zhang, W. Xu, Adv. Energy Mater. 6 (2016) 1502151.

[35] D. Aurbach, K. Gamolsky, B. Markovsky, Y. Gofer, M. Schmidt, U. Heider, Elec-trochim. Acta 47 (2002) 1423-1439.

[36] C. Yan, Y.X. Yao, X. Chen, X.B. Cheng, X.Q. Zhang, J.Q. Huang, Q. Zhang, Angew. Chem. Int. Ed. Engl. 57 (2018) 14055-14059.

[37] V. Shutthanandan, M. Nandasiri, J. Zheng, M.H. Engelhard, W. Xu, S. Thevuthasan,

V. Murugesan, J. Electron Spectros. Relat. Phenomena 231 (2019) 2-10.

[38] S. Tanaka, M. Taniguchi, H. Tanigawa, J. Nucl. Mater. 283-287 (2000) 1405-1408. 